\title{
- Constituintes do plasma seminal e suas interações com as células espermáticas
}

\section{- Seminal plasma components and their interaciones with spermatic cells}

\author{
Fabiana Ferreira de Souza ${ }^{1}$ - CRMV-SP $n^{\circ} 9003$ \\ Maria Denise Lopes ${ }^{2}$-CRMV-SPn ${ }^{0} 2519$ \\ Sony Dimas Bicudo ${ }^{3}$ - CRMV-SP n 2843
}

Departamento de

Reproduçāo Animal e

Radiologia Veterinária

Faculdade de Medicina

Veterinária e Zootecnia,

Universidade Estadual

Paulista (UNESP),

Câmpus de Botucatu

Distrito de Rubiāo Júnior $\mathbf{s} / \mathbf{n}$ 으,

Botucatu - SP

CEP-18.618-000.

E-mail:

fafesouza@yahoo.com

\footnotetext{
Doutoranda na área de Reprodução Animal, FMVZ, UNESP/BOTUCATU

Profa. Assistente Dra. Depto. Reprodução Animal e Radiologia Veterinária, FMVZ, UNESP/BOTUCATU

Prof. Assistente Dr. Depto. Reprodução Animal e Radiologia Veterinária, FMVZ, UNESP/BOTUCATU
}

\section{RESUMO}

A partir da introdução de técnicas de inseminação artificial, pouca importância tem sido dada ao plasma seminal, já que este é substituído por outros compostos diluidores. Contudo, o processo de monta natural, dificilmente poderia funcionar sem o plasma seminal como diluente para os espermatozóides concentrados no epidídimo. O estudo deste fluído desperta interesse, visto que, os diluidores seminais atuais, tentam de alguma forma substituí-lo. Desta maneira, se sua composição for totalmente revelada, seria mais fácil o processo de preservação do sêmen, principalmente naquelas espécies, onde hoje, se tem dificuldade em criopreservá-lo. Além disto, o conhecimento de "marcadores" de fertilidade, presentes no plasma seminal, seria de grande valia na identificação de animais de alto valor reprodutivo.

Unitermos: plasma seminal.

\section{Introdução}

A avaliação do ejaculado é de primordial importância para determinar a qualidade do sêmen e, desta forma, obter sucesso na inseminação artificial. Técnicas disponíveis são capazes de diagnosticar infertilidade ou subfertilidade e deveriam ser empregadas como exame de rotina em todos os machos. Em algumas espécies, como a bovina e a humana, estudos do perfil protéico do plasma seminal têm correlacionado a presença de certas proteínas à baixa ou alta fertilidade e a congelabilidade do sêmen. Contudo, a análise do sêmen total continua sendo um teste laboratorial inicial para determinar a fertilidade do macho, apesar de ser de valor duvidoso (AYYAGARI et al., 1987). A preservação dos gametas está condicionada aos conheci- mentos da bioquímica espermática e aos estudos dos componentes dos líquidos seminais e, principalmente, a sua interação com o meio e com o próprio espermatozóide (COULTER, 1992).

\section{Importância do plasma seminal}

O sêmen é composto por duas frações distintas: os espermatozóides, que compõe menos que $1 \%$ do volume total e o plasma seminal. A principal função do plasma seminal é servir como meio de transporte e sustentação para os espermatozóides (WITE, 1988). É o produto das secreções dos tecidos acessórios sexuais, como o epidídimo, o ducto deferente, a ampola, a vesícula seminal, a próstata, a glândula bulbouretral ou de Cowper e a glândula de Littre ou glândulas uretrais, em resposta à tes- 
SOUZA, F. F.; LOPES, M. D.; BICUDO, S. D. Constituintes do plasma seminal e suas interações com as células espermáticas. Revista de Educação Continuada do CRMV-SP / Continuous Education Journal CRMV-SP, São Paulo, volume 2, fascículo 2, p.089 - 095, 1999.

Figura 1 - Esquema representando os compartimentos do sistema reprodutor masculino dos mamíferos.

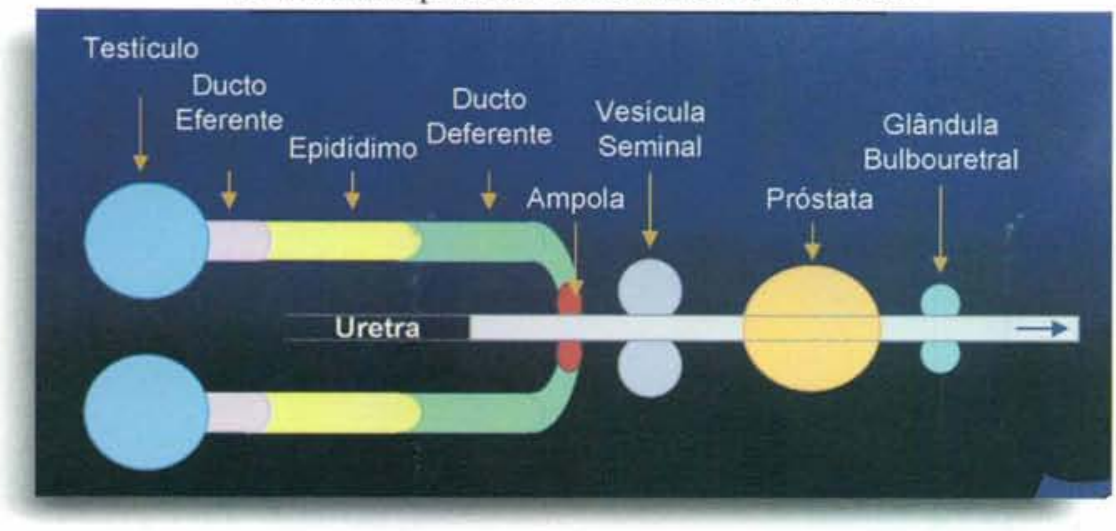

teínas de origem epididimal e/ou do plasma seminal, os fatores de decapacitação, que podem restringir o movimento de proteínas e lipídeos através da membrana. Posteriormente, ocorre aumento na proporção de colesterol:fosfolipídeos (PARRISH e FIRST, 1993) e conseqüentes modificações nos canais iônicos, induzindo o influxo transmembrana de íons metais, principalmente o cálcio $\left(\mathrm{Ca}^{+2}\right)$ (HOLT, 1984, WOLF et al., 1992, MANJUNATH et al., 1993, TULSIANI et al., 1997). A membrana se torna mais instável, propiciando a fusão da membrana plasmática à membrana acrossomal, formando

tosterona (WITE, 1988, PARRISH e FIRST, 1993). A Figura 1 representa todos os compartimentos, pelos quais os espermatozóides percorrem durante a produção, maturação, armazenamento e ejaculação. A função destas secreções, no processo de fecundação, ainda é duvidosa. Muitos estudos têm questionado a necessidade destas secreções no processo de fecundação; isto porque, em algumas espécies, os espermatozóides são capazes de fecundar após sua remoção do epidídimo, ou seja, sem nenhum contato com o produto de secreção destas glândulas. $\mathrm{O}$ plasma seminal pode não conter fatores extremamente essenciais para a fecundação, mas as secreções podem proporcionar condições para a motilidade, sobrevivência e transporte dos espermatozóides, tanto no trato reprodutor masculino, como no feminino (EWING e CHANG, 1986).

As interações entre as células espermáticas e o fluído seminal iniciam-se desde a espermatogênese, contudo, durante a passagem pelo epidídimo, a membrana plasmática dos espermatozóides sofre extensivas alterações biológicas (TULSIANI et al., 1997, NAABY-HANSEN et al., 1997). Como os espermatozóides perdem toda a capacidade de sintetizar e secretar proteínas na espermatogênese (SHABANOWITZ e KILLIAN, 1987), novas proteínas são aderidas pela interação da célula espermática como meio. Todas as modificações na membrana plasmática, durante a maturação epididimal, regulam a capacidade espermática para movimentação e ligação à zona pelúcida (VARRICCHIO et al., 1996).

Dois eventos principais estão relacionados à fecundação do gameta feminino. A capacitação espermática e a reação acrossomal. As alterações iniciais na membrana plasmática, durante o processo de capacitação, envolvem a remoção periférica de pro- vesiculações. Estes acontecimentos promovem a liberação das enzimas acrossomais, por exocitose, que proporcionarão a fecundação do oócito. Estes processos estão diretamente correlacionados às interações do plasma seminal, célula espermática e o fluído do trato reprodutor feminino (PARRISH e FIRST, 1993). A Figura 2 representa um esquema da capacitação e reação acrossomal.

Recentes estudos, têm demonstrado a importância do plasma seminal. Na espécie eqüina, a adição de plasma seminal de garanhões de alta fertilidade à espermatozóides de animais de baixa fertilidade elevou a resistência do espermatozóide à congelação e descongelação, concluindo que a composição do plasma seminal é um fator que determina a susceptibilidade individual de garanhões para a criopreservação do sêmen (AURICH et al., 1996). Em bovinos, HENAULT e KILLIAN (1996) notaram aumento na taxa de penetração de oócitos por espermatozóides de animais de

Figura 2 - Esquema dos principais eventos da capacitação espermática e reação acrossomal (secção sagital da cabeça de um espermatozóide bovino).

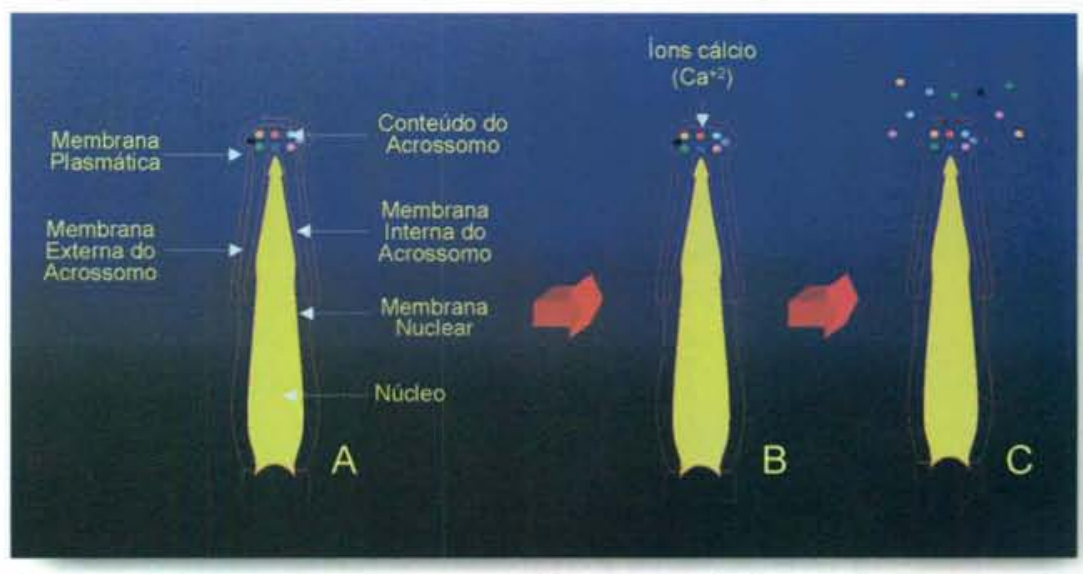

A - Compartimentos da cabeça espermática. B - Início da capacitação espermática, com influxo de íons cálcio $\left(\mathrm{Ca}^{+2}\right)$ e desestabilização das membranas plasmática e acrossomal. C - Fusão, seguida de vesiculação da membrana plasmática e acrossomal da cabeça espermática, com liberação do conteúdo acrossomal. 


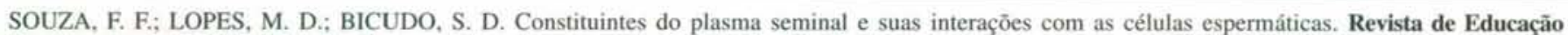
Continuada do CRMV-SP / Continuous Education Journal CRMV-SP. São Paulo, volume 2, fascículo 2, p.089 - 095 , 1999.

Tabela I - Concentração de alguns componentes do plasma seminal de várias espécies (Baseado em EWING e CHANG, 1986, WITE, 1988, SETCHELL, 1993).

\begin{tabular}{|c|c|c|c|c|c|c|}
\hline COMPONENTES & HOMEM & TOURO & CARNEIRO & VARRĀO & GARANHĀO & CĀO \\
\hline Proteinas (mg/100 ml) & 4 & $3-8$ & $5(\mathrm{ST})$ & 3.7 (ST) & $1.0(\mathrm{ST})$ & 2.1-3.7 \\
\hline Frutose $(\mathrm{mg} / 100 \mathrm{ml})$ & 222 & $120-600$ & $150-600$ & $9-40$ & $<1(0-6)$ & $<1$ \\
\hline Sorbitol (mg/100 ml) & 10 & $10-136$ & $26-120$ & $6-18$ & $20-60$ & $<1$ \\
\hline Ácido Cítrico $(\mathrm{mg} / 100 \mathrm{ml})$ & 376 & $357-1000$ & 137 & $36-325$ & $8-53$ & $4-30$ \\
\hline Ácido Ascórbico (mg/100 ml) & 13 & 8.7 & 5 & & & \\
\hline Inositol (mg/100 ml) & 50 & $25-46$ & $10-15$ & $380-610$ & $19-47$ & \\
\hline Ergotioneina $(\mathrm{mg} / 100 \mathrm{ml})$ & & $0(\mathrm{ST})$ & $0(\mathrm{ST})$ & $6-30$ & $3.5-13.7$ & \\
\hline Ácido Glutâmico (mg/100 ml) & & $35-41$ & 76 & & & \\
\hline $\begin{array}{l}\text { Glicerilfosforilcolina } \\
(\mathrm{mg} / 100 \mathrm{ml})\end{array}$ & 66 & $110-500$ & $1600-2000$ & $110-240$ & $40-100$ & $\begin{array}{r}180 \\
\text { (ST) }\end{array}$ \\
\hline Sódio $(\mathrm{mg} / 100 \mathrm{ml})$ & 650 & 270 & 180 & 280 & 260 & 260 \\
\hline Potássio (mg/100 ml) & 440 & 170 & 90 & 60 & 10 & 3 \\
\hline Cálcio (mg/100 ml) & 110 & 37 & 7.6 & 6 & 26 & 1.4 \\
\hline Magnésio $(\mathrm{mg} / 100 \mathrm{ml})$ & 27 & 8.2 & 5.9 & $11(\mathrm{ST})$ & 9 & 0.6 \\
\hline Cloreto $(\mathrm{mg} / 100 \mathrm{ml})$ & 550 & 174 & 64 & 340 & 448 & 540 \\
\hline Bicarbonato (Mmol/l) & & $\begin{array}{r}7.1 \\
\text { (ST) } \\
\end{array}$ & $\begin{array}{r}7.1 \\
\text { (ST) } \\
\end{array}$ & & & $\begin{array}{r}2.9 \\
\text { (ST) } \\
\end{array}$ \\
\hline$\alpha$-Manosidase (unid/ml) & & 400 & 50 & & & \\
\hline $\begin{array}{l}\beta-\mathrm{N}-\text { Acetilglucosaminidase } \\
\text { (unid/ml) }\end{array}$ & & 15000 & 16000 & & & \\
\hline
\end{tabular}

(ST: concentração do componente no sêmen total)

baixa fertilidade devido à adição de plasma seminal de animais de alta fertilidade. HENAULT et al. (1995) demonstraram que a capacidade de espermatozóides colhidos da cauda do epidídimo de touros de baixa fertilidade em penetrar oócitos aumenta significativamente quando expostos aos fluídos das glândulas sexuais acessórias de touros de alta fertilidade.

\section{Principais constituintes do plasma seminal e suas interações com as células espermáticas}

O plasma seminal é um meio isotônico e neutro que representa grande interesse bioquímico, pois apresenta compostos inorgânicos que não são encontrados em outras partes do organismo em concentrações tão elevadas (WITE, 1988).

Vários estudos sugerem que o plasma seminal contém fatores que podem influenciar a fertilidade nos machos. Alguns fatores têm sido isolados, tais como íons, proteínas e lipídeos. Dentre eles, as proteínas são os principais alvos de estudos. A presença, ausência ou a concentração de proteínas no plasma seminal são responsáveis pelos efeitos deste fluído na fertilidade espermática (HE-
NAULT e KILLIAN, 1996). A concentração de alguns componentes do plasma seminal de diversas espécies está representada na Tabela L. O resumo do principais componentes do plasma seminal está representado na Tabela II.

\section{Eletrólitos}

A composição iônica do plasma seminal varia nas diferentes espécies. Os principais íons do plasma seminal são: sódio, potássio, cloreto, cálcio e o magnésio. $\mathrm{O}$ sódio e o potássio se encontram em maior concentração e o cálcio e magnésio em menor quantidade (WITE, 1988). O cloreto é considerado o principal íon inorgânico do plasma seminal canino (JAMES et al., 1979). Alguns relatos indicam que o potássio está correlacionado com a viabilidade espermática (WITE, 1988). No cão a presença do sódio e do potássio foi correlacionada à motilidade espermática (JAMES et al., 1979).

O cálcio é um importante regulador da fisiologia espermática. Sua concentração é muito maior no plasma seminal quando comparada ao sangue. É secretado principalmente pela próstata, mas uma pequena parte tem origem na vesícula seminal. Está envolvido em várias eta- 
SOUZA, F. F: LOPES, M. D.: BICUDO, S. D. Constituintes do plasma seminal e suas interações com as células espermáticas. Revista de Educação Continuada do CRMV-SP / Continuous Education Journal CRMV-SP. São Paulo, volume 2, fascículo 2, p.089 - 095 , 1999.

Tabela II:

Resumo dos principais constituintes do plasma seminal dos mamíferos.

\section{Principais constituintes do plasma seminal}

\section{Eletrólitos}

- Sódio, potássio, cloreto, magnésio, cálcio, zinco, bicarbonato, citrato

\section{Carboidratos}

- Frutose, glicose, sorbitol, inositol, ribose, fucose, ácido ascórbico, ácido cítrico, ácido glutâmico, $\mathrm{N}$-acetilglicosamina

\section{Compostos Nitrogenados}

- Lecetinas, cefalinas, glicerilfosforilcolina, fosforilcolina

\section{Proteinas}

- Proteínas básicas e ácidas de baixo e alto peso molecular, albumina, imunoglobulinas, calmodulina, BSPs (proteínas do plasma seminal bovino), HPBs (proteínas ligadoras de heparina)

\section{Aminoácidos}

Básicos, ácidos e neutros

Enzimas

- Fosfatase ácida prostática (PAP), antígeno específico prostático (PSA), fosfatase alcalina (FA), leucina aminopeptidase, B-glucoronidase, dehidrogenase láctica, diamina oxidase, $\alpha$-amilase, fibrinolisina, semina, $\alpha$-manosidase, $B-N$ acetilglucosaminidase, aspartatoamino-transferase, arginina esterase

Lipideos e Ácidos Graxos Livres

- Fosfolipídeos (esfingomielina, etanolamina, fosfatidilcolina), colesterol, diglicerídeos, triglicerídeos, éster ceroso

\section{Prostaglandinas}

A, B, E e F

Fatores de Coagulação e Liqüefação Seminal

- Vesiculase, sialomucoproteína, antígeno específico prostático (PSA) e outras enzimas proteolíticas

\section{Outros}

Ergotioneína, hormônios (andrógenos, estrógenos e prolactina)

pas da maturação, da capacitação e da reação acrossomal dos espermatozóides. KILIÇ et al. (1996) estudaram a relação entre a concentração de cálcio total e ionizado $\left(\mathrm{Ca}^{+2}\right)$ e a motilidade progressiva dos espermatozóides. Demonstraram que pacientes com baixa contagem espermática e desordens na motilidade apresentavam concentrações diminuídas do cálcio ionizado no fluído seminal, concluindo que as concentrações de cálcio total e ionizado podem servir como um sensível indicador para a motilidade espermática.
O zinco do plasma seminal é produzido pela próstata, e é considerado um fator antibacteriano para gram negativas e positivas (EWING e CHANG, 1986) e potente anti-oxidante (GAVELLA e LIPOVAC, 1998). Um estudo revelou que as concentrações de zinco no plasma seminal não diferem significantemente em homens normospérmico, oligospérmico e azoospérmico (SCHOENFELD et al., 1979). Contudo, PANGAWKAR et al. (1988) correlacionaram os níveis de zinco à congelabilidade do sêmen em búfalos. Verificaram que animais que demonstravam menores concentrações de zinco no plasma seminal, a congelação do sêmen foi prejudicada, concluindo que este elemento pode interferir na integridade da membrana espermática.

No homem, o citrato é o principal íon presente no plasma seminal e sua fonte primária é a próstata. É importante na manutenção do equilíbrio osmótico prostático, sendo um importante ligador de íons metais (EWING e CHANG, 1986, PARRISH e FIRST, 1993).

\section{Carboidratos}

A frutose é o principal açúcar presente no plasma seminal do homem, touro, carneiro, varrão, caprino e coelho que serve como fonte de energia aeróbica e anaeróbica (EWING e CHANG, 1986), com exceção dos caninos, felinos e eqüinos que possuem pequena quantidade de frutose no sêmen e níveis muito baixos de açúcares seminais (WITE, 1988). É secretada pela vesícula seminal e metabolizada em ácido láctico pelos espermatozóides (STABENFELDT e EDQVIST, 1988, WITE, 1988, GUYTON, 1991). A vesícula seminal também secreta pequenas quantidades de outros açúcares como a glicose, sorbitol, inositol, ribose e fucose (EWING e CHANG, 1986, WITE, 1988). O inositol, um carboidrato não-redutor, pode também estar presente em algumas espécie em concentrações elevadas, como nos suínos (STABENFELDT e EDQVIST, 1988).

$\mathrm{O}$ ácido cítrico está localizado em diferentes tecidos sexuais acessórios de acordo com a espécie (EWING e CHANG, 1986). Está presente no plasma seminal em altas concentrações, com exceção dos eqüinos e caninos, todavia, não é utilizado pelos espermatozóides, provavelmente em conseqüência da impermeabilidade da membrana (WITE, 1988).

$\mathrm{O}$ ácido ascórbico está presente principalmente no plasma seminal de touros e no homem (SETCHELL, 1993), sendo considerado potente redutor, prevenindo os efeitos tóxicos da oxidação (STABENFELDT e EDQVIST, 1988). 


\section{Compostos nitrogenados}

O sêmen é rico em colina, que pode estar sob várias formas: lecitinas, cefalina e glicerilfosforilcolina. No homem, a fosforilcolina é predominante, sendo substrato específico da enzima fosfatase ácida prostática, que quebra este composto em colina livre. Na maioria das espécies, os níveis são mais elevados de $\alpha$-glicerilfosforilcolina (EWING e CHANG, 1986). A $\alpha$-glicerilfosforilcolina é sintetizada a partir da lecitina pelo epidídimo (SETCHELL, 1993). Na espécie ovina, sua função é servir como fonte de energia para os espermatozóide pela via glicolítica no trato reprodutor feminino (WITE, 1988).

O maior grupo ativo de poliaminas no plasma seminal são espermina e espermidina, as quais são produzidas apenas pela próstata no homem (STABENFELDT e EDQVIST, 1988). A função biológica destas poliaminas é desconhecida, mas acredita-se que o nível de espermina no plasma seminal apresenta alguma relação com a concentração, motilidade espermática e proteção do trato geniturinário contra patógenos (EWING e CHANG, 1986).

\section{- Proteínas, aminoácidos e enzimas}

O conteúdo protéico do plasma seminal de mamíferos varia de 3 a 7\%, dependendo da espécie (WITE, 1988). Alguns estudos têm demonstrado que as proteínas aderidas à membrana espermática são semelhantes àquelas existentes no plasma seminal. Este fato sugere que estas proteínas são provenientes da interação plasma seminal e células espermática e que apresentam importante papel no processo de fecundação (VIURELLA e RAJANIEMI, 1980).

Nos suínos, o plasma seminal apresenta alta concentração de proteínas básicas originárias da vesícula seminal, que aumentam a susceptibilidade da membrana espermática a danos durante os processos de congelação e descongelação (MOORE e HIBBITT, 1976). Animais, que a vesícula seminal foi retirada, apresentaram ejaculados férteis, embora demonstraram redução dramática na quantidade de proteínas do plasma seminal, além de alterações na carga superficial da membrana. Contudo, notou-se maior resistência a danos citoplasmáticos pelo choque térmico (METZ et al., 1990). KILLIAN et al. (1993) estudaram as proteínas do plasma seminal de touros por eletroforese em gel de poliacrilamida e sugeriu a existência de 4 proteínas associadas à fertilidade.

Embora BAAS et al. (1983) tenham sugerido efeito prejudicial aos espermatozóide de proteínas de alto peso molecular do plasma seminal bovinos, GARCIA e GRAHAM (1987) demonstraram que a alta concentração de proteínas de baixo peso molecular, causa aumen- to na permeabilidade da membrana celular espermática, promove choque térmico e injúrias às células durante a congelação e a descongelação. Posteriormente, AL-SOMAI et al. (1994) encontraram que somente componentes de baixo peso molecular são deletérios para os espermatozóides. PANGAWKAR et al. (1988) verificaram, em búfalos, que a criopreservação do sêmen foi prejudicada pelo aumento da concentração de proteínas totais do plasma seminal.

Calmodulina é uma proteína ácida de baixo peso molecular que possui a capacidade de regular processos celulares dependentes de cálcio, apresentando papel importante na prevenção da capacitação e da reação acrossomal precoces. Várias proteínas espermáticas têm sido identificadas como ligadoras de calmodulina que possuem a função de regular sua atividade. MANJUNATH et al. (1993) demonstraram que a heparina diminui a ligação das "proteínas ligadoras" à calmodulina, induzindo maior influxo de íons cálcio nas células espermáticas durante a capacitação.

As BSPs (proteínas do plasma seminal bovino), produtos secretórios da vesícula seminal, se ligam à superfície espermática após a ejaculação e interagem com a calmodulina (DESNOYERS e MANJUNATH, 1992). Acredita-se que parte das BSPs podem ser inseridas dentro da membrana plasmática após estabelecer uma comunicação com a calmodulina. As BSPs também podem se ligar à heparina, e isto levaria à diminuição da ligação à calmodulina e, concomitantemente, entrada de íons cálcio no espermatozóide, iniciando a capacitação (MANJUNATH et al., 1993).

As HPBs (proteínas ligadoras de heparina), secretadas pelas glândulas sexuais acessórias, estão presentes no plasma seminal. Estas proteínas se ligam a membrana espermática e são ligadoras de heparina e de glicosaminoglicanas (GAGs). As GAGs são proteínas estruturalmente semelhantes à heparina e estão presentes na zona pelúcida. Acredita-se que as HPBs participam do processo de fecundação, ligando-se às GAGs, assim como a heparina, estando diretamente correlacionada ao processo de capacitação (MULLER et al., 1990).

O plasma seminal pode conter anticorpos, contudo a fonte é desconhecida (EWING e CHANG, 1986).

As duas principais enzimas do plasma seminal humano, produzidas pela próstata, são a fosfatase ácida (PAP) e o antígeno específico prostático (PSA), reconhecidas como marcadores de carcinoma prostático (STAMEY et al., 1994). A função da PAP é ainda obscura, mas é capaz de clivar diversas proteínas (OSTROWSKI e KUCIEL, 1994). O PSA cliva a semenogelina, produto da vesícula seminal responsável pela coagulação 
SOUZA, F. F: LOPES, M. D.: BICUDO, S. D. Constituintes do plasma seminal e suas interações com as células espermáticas. Revista de Educação Continuada do CRMV-SP / Continuous Education Journal CRMV-SP, São Paulo, volume 2, fascículo 2, p.089 - $095,1999$.

do sêmen humano, a fim de liqüefazer o ejaculado (ARMBRUSTER,1993). Tanto o PSA, como a PAP já foram detectadas por imunohistoquímica na próstata canina (McENTEE et al., 1987).

\section{Lipídeos, ácidos graxos livres e prostaglandinas}

Os fosfolipídeos constituem a maior fração lipídica do plasma seminal do touro, varrão e garanhão (WITE, 1988). O principal local de produção lipídica é a próstata, sendo o colesterol o principal composto. A fração de colesterol/fosfolipídeos no plasma seminal tem como função estabilizar a membrana espermática contra choques térmicos do meio ambiente (EWING e CHANG, 1986). $\mathrm{O}$ aumento da susceptibilidade do espermatozóide ao choque térmico está correlacionado com o baixo conteúdo de colesterol na membrana plasmática. Fatores que inibem o efluxo de colesterol do espermatozóide aumentam a resistência ao choque térmico. Diferenças individuais no conteúdo do plasma seminal de fatores de estabilização da membrana espermática poderiam justificar as diferenças entre os animais na congelabilidade do espermatozóide (AURICH et al., 1996).

As prostaglandinas são compostos derivados de ácidos graxos não saturados (WITE, 1988). A maior fonte de prostaglandina no homem é a vesícula seminal. Contudo, nos suínos, origina-se da vesícula seminal e da próstata (STABENFELDT e EDQVIST, 1988). Estes compostos são responsáveis pela dissolução da secreção va- ginal e do muco cervical e pelo transporte espermático até o oócito (GUYTON, 1991).

\section{Fatores de coagulação e liquefação do sêmen}

O sêmen de muitas espécies coagula-se após a ejaculação. Este fenômeno é observado em roedores, suínos, macacos e no homem. Este processo difere da coagulação sangüínea. No homem, o sêmen coagula em gel semi-sólido dentro de 5 minutos seguidos à ejaculação; após 5 a 20 minutos, o coágulo se desfaz formando líquido viscoso. O processo de liqüefação seminal é feito por enzimas proteolíticas (EWING e CHANG, 1986).

\section{Outros}

Ergotioneína, uma base que contém enxofre e previne os efeitos tóxicos de agentes oxidantes (STABENFELDT e EDQVIST, 1988) está presente em altas concentrações no plasma seminal de suínos e de eqüinos (WITE, 1988).

Os hormônios também podem ser encontrados no plasma seminal entre eles, podemos destacar os andrógenos, estrógenos e prolactina. Alguns autores têm mostrado que os níveis de prolactina no plasma seminal de homens normospérmicos são significantemente mais altos que em homens oligospérmicos ou azoospérmicos. Contudo, o significado destes achados não foi determinado (SCHOENFELD et al., 1979).

\section{SUMMARY}

With the increaseing use of artificial insemination techniques, little importance has been given to seminal plasma, since it is substituted by other diluters. However, natural sexual intercourse would not work without seminal plasma as diluter for spermatozoa in the epididimus. The study of seminal plasma brings important information for the research on diluters, which are made to substitute the forme. Thus, if the seminal plasma compositio were known, it would be easeier to preserve semen samples, specially those of species that present cryopreservation problems. Beside, knowledge on "fertility markers" that may be present in seminal plasma would be of breat importance in the identification of animals of high reproductive value.

Uniterms: seminal plasma.

\section{REFERÊNCIAS BIBLIOGRÁFICAS}

1 - AL-SOMAI, N., VISHWANATH, R., SHANNON, P. et al. Low molecular weight components in bovine semen diffusate and their effects on motility of bull sperm. Reprod. Fert. Dev., v.6, p.165-71, 1994.

2 - ARMBRUSTER, D. A. Prostate-specific antigen: biochemistry, nalytical methods, and clinical application. Clin.
Chem., v.39, p.181-95, 1993.

3 - AURICH, J. E., KÜHNE, A., HOPPE, H. et al. Seminal plasma affects membrane integrity and motility of equine spermatozoa after cryopreservation. Theriogenology, v.46, p.791-7, 1996.

4 - AYYAGARI, R. R., FAZLEABAS, A. T., DAWOOD, M. Y. 
Seminal plasma proteins of fertile and infertile men analyzed by two-dimensional electrophoresis. Am. J. Obstet. Gynecol., v.157, p.1528-33, 1987.

5 - BAAS, J. W.. MOLAN, P. C., SHANNON, P. Factors in seminal plasma of bulls that affect the viability and motility of spermatozoa. J. Reprod. Fert., v.68, p.275-80, 1983.

6 - COUlter, G. H. Bovine spermatozoa in vitro: a review of storage, fertility estimation and manipulation. Theriogenology, v.38, p.197-207, 1992.

7 - DESNOYERS, L., MANJUNATH, P. Major proteins of bovine seminal plasma exhibit novel interactions with phospholipd. J. Biol. Chem., v.267, p.10149-55, 1992.

8 - EWING, L. L., CHANG, T. S. K. Physiology of male reproduction. In: WALSH, P. C., GITTES, R. F., PERLMUTTER, A. D. et al. Campbell's urology. Philadelphia:W. B. Saunders, 1986, p.200-74.

9 - GARCIA, M. A., GRAHAM, E. F. Dialysis of bovine semen and its effect on fresh and freeze-thawed spermatozoa. Cryobiology, v.24, p.446-54, 1987.

10 - GAVELA, M., LIPOVAC, V. In vitro effect of zinc on oxidative changes in human semen. Andrologia, v.30, p.317-23, 1998.

11 - GUYTON, A. C. Textbook of medical physiology. 8.ed. Philadelphia: W. B. Saunders, 1991, p.885-98: Reproduction and hormonal functions of the male.

12 - HENAULT, M. A., KILLIAN, G. J. Effect of homologous and heterologous seminal plasma on the fertilizing ability of ejaculated bull spermatozoa assessed by penetration of zona-free bovine oocytes. J. Reprod. Fert., v.108, p.199-204, 1996.

13 - HENAULT, M. A., KILLIAN, G. J., KAVANAUGH, J. F. et al. Effect of acessory Sex gland fluid bulls of differing fertilities on the ability of cauda epididymal sperm to penetrate zona-free bovine oocytes. Biol. Reprod., v.52, p.390-7, 1995 (Abstract).

14 - HOLT, W. V. Membrane heterogeneity in the Mammalian spermatozoon. Int. Rev. Citol., v.87, p.159-94, 1984.

15 - JAMES, R. W., HEYWOOD, R., STREET, A. E. Biochemical observations on beagle dog semen. Vet. Rec., v. 104, p.4802, 1979.

16 - KILIÇ, S., SARICA, K., YAMAN, Ö. et al. Effect of total and ionized calcium levels of seminal fluid on sperm motility. Urol. Int., v.56, p.215-8, 1996.

17 - KILliAN, G. J., CHAPMAN, D. A., ROGOWSKI, L. A. Fertility-associated proteins in Holstein bull seminal plasma. Biol. Reprod., v.49, p.1202-7, 1993.

18 - MANJUNATH, P., CHANDONNET, L., BAILLARGEON, L. et al. Calmodulin-binding proteins in bovine semen. $\mathbf{J}$. Reprod. Fert., v.97, p.75-81, 1993.

19 - McENTEE, M., ISAACS, W. SMITH, C. Adenocarcinoma of the canine prostate: immunohistochemical examination for secretory antigens. Prostate, v.11, p.163-70, 1987.

20 - METZ, K. W., BERGER, T., CLEGG, E. D. Adsorption of seminal plasma proteins by boar spermatozoa. Theriogenology, v.34, p.691-700, 1990.

21 - MOORE, H. D. M., HIBBITT, K. G. The binding of labelled basic proteins by boar spermatozoa. J. Reprod. Fert. v.46, p.71-6, 1976.
22 - MULLER, D. J., WINER, M. A., AX, R. L., Heparin-binding proteins from seminal plasma bind to bovine spermatozoa and modulate capacitation by heparin. Biol. Reprod., v.42, p.899-915, 1990.

23 - NAABY-HANSEN, S., FLICKINGER, C. J., HERR, J. C., Two-dimensional gel electrophoretic analysis of vectorially labeled surface proteins of human spermatozoa. Biol. Reprod., v.56, p.771-87, 1997.

24 - OSTROWSKI, W. S., KUCIEL, R. Human prostatic acid phosphatase: selected properties and practical applications. Clin. Chem. Acta, v.226, p.121-9, 1994.

25 - PANGAWKAR, G. R., SHARMA, R. D., SINGH, R. Protein, sialic acid and zinc concentration in the seminal plasma of bulls in relation to freezability of semen, Ind. Vet. J., v.65, p.58-60, 1988.

26- PARRISH, J. J., FIRST, N. L. Fertilization. In: KING, G. J., NEIMANN-SORENSEN, A., TRIBE, D. E. World animal science-Reproduction in domesticated animals. New York: Elsevier., 1993, p.195-227.

27 - SCHOENFELD, C. Y., AMELAR, R. D., DUBIN, L. et al. Prolactin, fructose, and zinc levels found in human seminal plasma. Fertil. Steril., v.32, p.206-8, 1979.

28 - SETCHELL, B. P. Male reproduction. In: KING, G. J., NEIMANN-SORENSEN, A., TRIBE, D. E. World animal science-Reproduction in domesticated animals. New York: Elsevier, 1993, p.83-127.

29 - SHABANOWITZ, R. B., KILLIAN, G. J. Two-dimensional electrophoresis of proteins in principal cells, spermatozoa, and fluid associated with the rat epididymis. Biol. Reprod., v.36, p.753-68, 1987.

30 - STABENFELDT, G. H., EDQVIST, L. Processos reprodutivos no macho. In: SWENSON, M. J. DUKES-Fisiologia dos animais domésticos. 10.ed. Rio de Janeiro:Guanabara, 1988, p.719-30.

31 - STAMEY, T., EKMAN, P., BLANKENSTEIN, M. et al. Tumor markers. Scand. J. Urol. Nephr., v.162, suppl., p.73-87, 1994

32 - TULSIANI, D. R. P., YOSHIDA-KOMIYA, H., ARAKI, Y. Mammalian fertilization: a carbohydrate-mediated event. Biol. Reprod., v.57, p.487-94, 1997.

33 - VARRICCHIO, E., LANGELLA, M., MAHARAJAN, V. et al. Structure and function of the mammalian epididymis. Acta Med. Vet., v.42, p.221-34, 1996.

34 - VIURELLA, M., RAJANIEMI, H. Radioiodination of surface proteins of bull spermatozoa and their characterization by sodium dodecyl sulphate- polyacrylamide gel electrophoresis. J. Reprod. Fert., v.58, p.483-9. 1980 .

35 - WITE, I. G. Secreções do trato reprodutivo masculino e plasma seminal. In: HAFEZ, E. S. E. Reprodução animal. 4.ed. São Paulo: Manole, 1988, p.212-28.

36 - WOLF, D. E., MCKINNON, C. A., LEYTON, L. et al. Protein dynamics in sperm membranes: implications for sperm function during gamete interaction, Mol. Reprod. Dev., v.33, p.228-34, 1992. 